\title{
INVESTIGACIONES ARQueOLÓGICAS EN EL MONTE de Nubes.
}

\author{
Alberto Bueno Mendoza
}

L a adaptación humana al bosque nuboso alto es un proceso de establecimiento de vida activa y respuesta cultural de supervivencia, cuya adaptabilidad debe ser comprendida en terminos de la capacidad intrínseca de cohesión del sistema cultural, explicando la estabilidad de larga duración de los asentamientos y sus complejidades multiculturales.

Plantea la hipótesis de una relación entre los vibaros intermedio tempranos y las culturas interandino como Pashash y Mareaguamachuco.

The human adaptation to the cloudy forest is a process of establishment of active life and cultural answer of survival, whose adaptability must be understood in terms of the inner capacity of cohesion of the cultural system, explaining the long term multicultural stability of the settlements and its complexities.

The author proposes a relation between the jiraros of the early intermediate period and the interandean cultures like Pashash and Mareaguamachuco. 


\section{Introducción}

En las regiones de San Martín y Amazonas se han explorado los territorios teniendo en cuenta las cuencas de los ríos Utcubamba, Vilaya, Pajatén, Abiseo, Apisoncho, Montenegro, Guabayacu, Guallabamba, Huallaga, etc. Las exploraciones y reconocimientos arqueológicos permiten conocer los territorios, localizar morfologías topográficas, reconocer laderas montuosas, farallones y recorrer redes fluviales no mapeadas, estudiar los ecosistemas de las cuencas y descubrir y localizar sitios arqueológicos nuevos de la mayor importancia para el conocimiento.

Así entonces, la investigación arqueológica en el nororiente peruano viene realizando descubrimientos de nuevos sitios, ejecutando excavaciones técnicocientíficas, registrando los datos en forma contextualizada y clasificada y estudiando los materiales muebles e inmuebles, orientados a precisar los problemas del poblamiento en los diversos períodos arqueológicos e identificar a la gente ocupante de los sitios conocidos al presente.

El Proyecto de Prospecciones y Excavaciones Arqueológicas en la Cuenca de los ríos Guayabamba y Guabayacu del Departamento de San Martín ha cumplido con las prescripciones técnicas en el campo; la deforestación en cerro Las Cruces ha sido de especies vegetales mínimas: los grandes árboles no han sido tocados; tal deforestación controlada ha sido necesaria para desbrozar el monte cobertor y así poder identificar y registrar la arquitectura arqueológica de caracteres monumentales conservada tapada por la vegetación. En el caso de la arquitectura arqueológica estudiamos las plantas arquitectónicas, alzadas construidas, materiales constructivos, los aparejos murarios, las técnicas constructivas, el espacio interno construido y cornisas, vanos y cubiertas, etc., extendiéndose los análisis a los ornamentos murarios tales como cabezas clavas, cruces, grecas escalonadas y otros diseños geométricos, etc.

En la margen derecha del río Marañón (provincia de Bolívar) se extiende una serie de quebradas con laderas y cortas planicies que dan lugar a cuestas hasta llegar al verde valle donde se asienta la ciudad de Bolívar, la que se encuentra al pie de la cumbre del gran cerro Cajamarquilla (5,200 m.s.n.m.), el que se cubre de hielo, escarcha y nieve durante las granizadas y nevadas de los meses de junio, julio y agosto. Toda su superficie alta está cubierta de ichupaja hasta la altipampa de Yonán (3,600 m.s.n.m.).

La información etnográfica actual señala presencia de fauna oriunda entre la sierra y selva nubosa alta tales como: venados, zorros, osos de anteojos, venado rojo, picuro, sachazorro, pumas, vizcacha, cuyes silvestres, etc.; avifauna: cóndor, gallinazo (shingo), huachua (wallata), patos silvestres, gavilán, halcón, cernícalo, lechuza, tucos, qoraquenque (tamaño grande: cuerpo negro, pecho y cola blanca), pava de monte (plumas negras), pava de monte (plumas blancas), paujiles, etc. 
Los terrenos de la planicie de Yonán están cubiertos de vegetación arbustiva y pastos rastreros, sobre mantos sedimentarios y terrazas rocosas naturales aflorantes. En el fondo de esta planicie, lado derecho, se encuentran dos lagunas a 3,550 m.s.n.m., desde donde nace el río Yonán, el que vierte por la quebrada del mismo nombre, y por la cual se ingresa a la cuenca de los ríos Guayabamba/Guabayacu.

Los pastores de la localidad señalan a los parajes de Unán $\left(220^{\circ}\right.$ norte) y Chivani (a dos horas de Yonán) como sitios arqueológicos ubicados en los sectores altos de la altipampa. Gran Chivani es un nombre de los sitios arqueológicos de los alrededores del pueblo de Uchuqmarka al norte de Bolívar, llamado así por el explorador norteamericano Gene Savoy.

En la misma altipampa de Yonán y próximo a las lagunas, ubicamos un sitio arqueológico de tipología local llamado Lomolargo; se trata de un asiento conformado por cuarenta y cinco unidades construidas a semidesnivel; veinticinco de ellas están protegidas de la humedad de las lagunas por una larga lomada baja, que según nuestras observaciones, es artificial, es decir, construida por los habitantes que edificaron las unidades constructivas arqueológicas, cuyas bases se conservan; en el lado opuesto, otras veinte unidades se encuentran hasta la falda baja de los cerros del lado izquierdo que delimitan a la altipampa. Estas edificaciones son pequeñas $(1.50 \times 1.00 \mathrm{~m}$.), tienen planta cuadrada y se observan alineadas con cierta irregularidad. En las faldas bajas de los cerros que rodean a la altipampa de Yonán, encontramos plantas de corrales cuadrados, circulares y alineamientos de piedras que cubren hasta el tercio medio de sus laderas.

A una hora de la altipampa de Yonán se encuentra Inkapirca (3,300 m.s.n.m.), sitio arqueológico conformado por tres unidades constructivas separadas: en este trabajo presentamos la que es unidad principal, reconocida in situ como la arquitectura Tawantinsuyu, ubicada en las cabeceras de la quebrada de Yonán. El camino arqueológico de estas laderas, en una u otra forma, estaría en relación con las edificaciones del área desde los tiempos Chacha, y habría sido mejorado por el Tawantinsuyu, al movilizarse en la región con muchas tropas. Hacia el noreste de Yonán, por la ladera derecha de la quebrada, el camino antiguo se dirige al sitio arqueológico Tawantinsuyu de Albitambo y de allí a la Peña de la Luna (pintura rupestre roja con el motivo «Luna»); desde este lugar continúa el camino hasta llegar al Tambo Pacarisca (Cooperativa Cujibamba-Bambamarca). Por la quebrada del río Yonán, margen izquierda, el camino que seguimos continúa muy malogrado por los fangos, hasta llegar al paraje «Cueva del Amor». En este trayecto, que dura dos horas de cabalgadura, se transita del bosque enano (3,245 m.s.n.m.) conformado por Polylepis, Cedrelinga, Chusque sp., podocarpus, etc., al bosque nuboso alto, cuyos cerros se caracterizan por empezarse a cubrir de tupida vegetación. El río Yonán discurre al fondo del cañón en «V». 
De la «Cueva del Amor» a Pampa Hermosa hay tres horas de camino por piso fangoso de ladera; en ciertos sectores se notan huellas de escaleras con piedras talladas; pero en el fondo fangoso ya no es observado. La llegada a Pampa Hermosa fue al caer la tarde (5.00 p.m.). El lugar presenta como característica unas veinte hectáreas de bosque talado; este talado debe haberse empezado en el siglo XVI, porque hay árboles tirados enormes (2.00 metros de ancho por 20.00 metros de largo promedio), los que están en estado de putrefacción por las lluvias, pero también como resultado del largo tiempo expuestos a ellas.

El lugar de Pampa Hermosa está directamente ubicado a la margen izquierda del río Yonán en el área de confluencia con el río Guayabamba, los que conforman el nacimiento del río Guabayacu. El nombre de Pampa Hermosa no pasa de unos sesenta años, por tanto, su nombre antiguo (Tawantinsuyu) es posible que haya sido "Guayabamba», aludiendo así a la presencia del nombre cusqueño vinculado al río aledaño a su confluencia. Pampa Hermosa (Guayabamba) es una zona arqueológica Tawantinsuyu emplazada durante el gobierno de Tupa Yupanki.

El viaje de Pampa Hermosa al campamento del Naranjo dura cuatro horas, caminando o cabalgando. En el trayecto se notan algunos tramos cortos de terrazas construidas con piedras de campo. Se camina intercambiando ambas márgenes del río Guabayacu. Los ríos que drenan por la margen derecha al Guabayacu son: el Tingo y el Bravo, ambos entre los parajes Papayal y El Naranjo. Los de su margen izquierda entre Pampa Hermosa y El Naranjo son: el río Jardín y el Pucallpa. Los campesinos de la localidad señalan que por la cuenca del río Jardín se viaja a la Región Amazonas.

A dos horas de Pampa Hermosa se llega al paraje del Papayal (cerca de la margen izquierda del río Tingo); el nombre del lugar se debe a que la familia propietaria campesina siembra árboles que dan unos frutos como papayas pequeñas en racimos llamados Chanfur. Dos horas después encontramos el paraje El Naranjo; ambos predios con su respectiva casa pertenecen a la familia Burgos, los únicos campesinos a la redonda. El campamento de El Naranjo se instala en la margen derecha del río Bravo; se trata del campamento base de la expedición, desde donde se parte a realizar las exploraciones y reconocimientos arqueológicos hacia ambas bandas del río Guabayacu. El regreso cumple el mismo trayecto en reversa.

Hacia el rumbo noreste la Selva Alta del Abiseo-Huallaga es un ecosistema extendido desde la Laguna Empedrada (3,840 m.s.n.m.) hasta el Pajatén (2,810 m.s.n.m.); esta parte de la selva alta del Abiseo-Huallaga presenta el tipo de clima frío, el cual se estima contaría con una precipitación entre 1,000 y 2,300 mm. anuales, notando que la precipitación por saturación de neblinas es propia de esta selva alta. Presenta un relieve variable que gradualmente va pasando de una pendiente casi plana en las partes más altas con farallones de roca a pendientes de mayor inclinación conforme se va descendiendo hacia la zona de Papayas y Vilcabamba y, luego, pasa 
Mapa de la Cuenca de los Ríos: Yonan-Guayabamba y Guabayacu

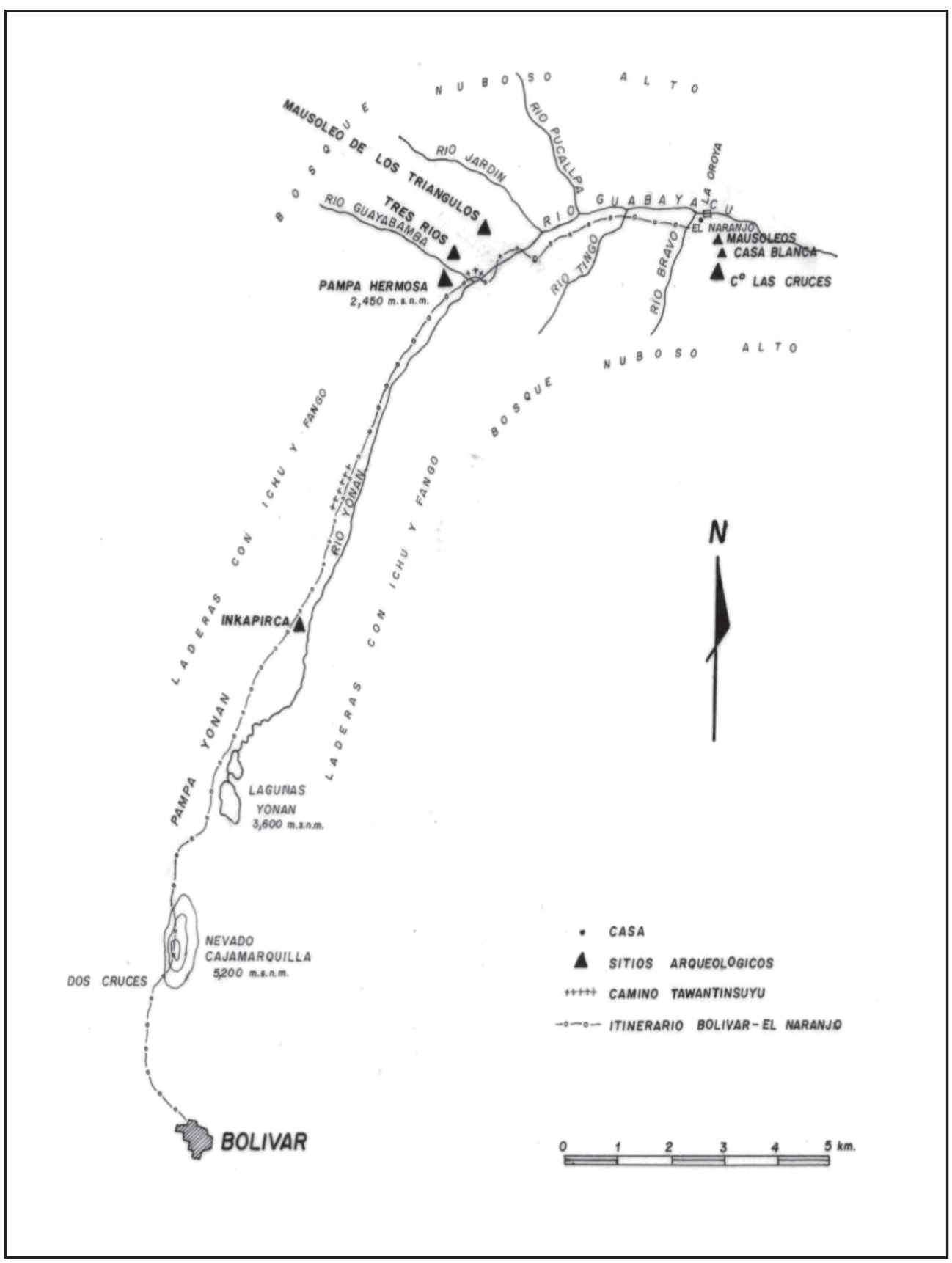


de empinada a vertical al ascender a la zona del Gran Pajatén, que se caracteriza por ser un territorio que va de plano a ligeramente inclinado.

La zona de Pinchudos se caracteriza por ubicarse en un afloramiento rocoso cubierto con vegetación asentada en sus grietas, y con una pendiente de casi $90^{\circ}$, por lo que no se observa la presencia de suelo, salvo en la base, que es similar a toda la zona del Gran Pajatén y Macedonio. Se presenta un valle en «U» en la zona de «Pampa de Cuyes» y los suelos son orgánicos, de mal drenaje (pudiendo llegar a formar pantanos), con presencia de pedregales cubiertos por bosques y por pajonal en las áreas donde no hay bosque. Esta ecorregión es atravesada por las Quebradas de Chochos, Jaboncillo y Susto, según el arqueólogo Anselmo Lozano Calderón (comunicación personal).

El sector El Churo consta de un ecosistema de Selva Baja o Bosque Tropical Amazónico, que se ubica en las tierras inferiores de la selva alta del Abiseo-Huallaga, la cual presenta una ecología típica de selva tropical amazónica, con presencia de diversidad de árboles de gran tamaño (mayor a $20 \mathrm{~m}$.), bosque denso y un estrato herbáceo continuo, así como una alta variedad de especies animales, entre las que sobresalen las aves como loros, guacamayos, el «shansho», entre otros y, luego, los mamíferos como los monos, jaguares, venados, etc., que son difíciles de observar.

Esta descripción ecosistémica tiene como finalidad informar acerca de las características fisiográficas y recursos naturales del territorio altoandino por el que se viaja al Gran Pajatén, Los Pinchudos, Cerro Central, etc. El nombre de Gran Pajatén fue adjudicado al sitio arqueológico por Gene Savoy (1965), quien arribó al sitio antes de la misión cívico-militar peruana del año 1967. Savoy realizó difusión y promoción mundial, a partir de lo cual, la zona arqueológica alcanzó mucha notoriedad.

Es notable señalar que el componente arqueológico de mayor significación en este territorio es el Qapaqñan que atraviesa la pampa conocida como Laplap; este gran camino Tawantinsuyu viene del sur (Huamachuco) pasa por el distrito de Tayabamba, atraviesa Pías (proximidades de la laguna del mismo nombre), se dirige a Condormarca (ya bajo el dominio cusqueño) y continúa a Cajamarca; de este camino un ramal secundario se dirige a la cuenca del río Yonán-Guayabamba y otros trayectos terciarios entraban a la cuenca del río Tepna y al Gran Pajatén/Cerro Central/Los Pinchudos.

La localización UTM del Gran Pajatén indica 235.175E, 9.153.473N y 2,900 m.s.n.m. de altitud. El sitio es monumental; los edificios principales conservan sus frisos parietales figurativo/geométricos de estilo Chacha. El Tawantinsuyu parece que administró el Gran Pajatén desde Kunturmarka y/o Pakarishka, sitios Tawantinsuyu en el borde de Jalca, antiguo dominio Chacha. Los caminos de piedra 
que se descubren y estudian en nuestros días traslucen las relaciones de poder sierrabosque de nubes, habiendo sido el Gran Pajatén y la cuenca de los ríos Yonán/ Guayabamba/Guabayacu, los que presentan cantidad de testimonios de ambos períodos arqueológicos Chacha y Tawantinsuyu, al oeste y suroeste de la región San Martín.

\section{Los Sitios Arqueológicos.}

\section{Sitios Chacha en la Cuenca de los ríos Yonán/Guayabamba y Guabayacu.}

1.1 Pampa Yonán (dos sectores de ocupación): sitio Lomolargo.

1.2 Pampa Hermosa A (sector alto).

1.3 La Rinconada (margen derecha baja del río Guayabamba).

1.4 Tres Ríos (asentamiento urbano alto del cerro de la margen izquierda donde nace el río Guabayacu).

1.5 Cedrobamba (pampa de Los Cedros y Cedro Alto): margen derecha del río Guabayacu.

1.6 Cerro Monte Unión (pocas unidades arquitectónicas): margen derecha del río Guabayacu.

1.7 El Naranjo (margen derecha baja del río Bravo): margen derecha del río Guabayacu.

1.8 Puente Oroya A/Puente Oroya B (parte alta): margen izquierda del río Guabayacu.

1.9 Cerro Las Cruces: gran sitio arqueológico y mausoleos asociados.

1.10 Los Triángulos (farallón alto de cerro): margen izquierda del río Guabayacu.

\section{Sitios Tawantinsuyu en la Cuenca de los ríos Yonán/Guayabamba/Guabayacu.}

2.1 Inkapirka: margen izquierda de las cabeceras del río Yonán.

2.2 Camino Tawantinsuyu Yonán/Pampa Hermosa/La Morada.

2.3 Pampa Hermosa B (gran asentamiento Tawantinsuyu emplazado contiguo a la unión de los ríos Guayabamba y Yonán, para formar el Guabayacu).

2.4 Inkapampa o Pakarumi (Río Israel, margen derecha).

2.5 La Morada (sitio Tawantinsuyu a $1 \mathrm{~km}$ del pueblo actual).

2.6 Materiales Tawantinsuyu en sitios y mausoleos Chacha.

Las características geofísicas de la Cultura Chachapoya establecieron interrelaciones entre el medio geográfico y sus hombres y mujeres, constituyendo un ecosistema humano como complejo múltiple dinámico de interrelación e interacción entre el geoambiente y los asentamientos socio-culturales. 
En general, los estudios arqueológicos en la cuenca del Río Marañón, provincias de Bolívar, Pataz y Tayabamba (La Libertad) y los sectores oeste y suroeste de la Región San Martín, permiten conocer el potencial existente de grandes sitios arqueológicos de Cultura Chachapoya en la margen derecha de este gran río, cuyas tierras de Jalca presentan lagunas, manantes de napa freática y cabeceras de ríos que discurren a la selva nubosa alta, por continuidad territorial sierra-selva alta (San Martín / Amazonas). Sitios reconocidos son los siguientes:

- $\quad$ Pirka-Pirka (distrito Uchucmarca, provincia Bolivar).

- Vira-Vira (provincia Bolivar).

- $\quad$ Cerro Yonán (distrito Saposoa, San Martín, Prov. Huallaga).

- $\quad$ Lomolargo de Yonán (distrito Saposoa, San Martín, Prov. Huallaga).

- $\quad$ Pampa Hermosa (distrito Saposoa, Prov. Huallaga, San Martín).

- $\quad$ Cerro Las Cruces (distrito Saposoa, Prov. Huallaga, San Martín).

- $\quad$ Cerro Tres Ríos (distrito Saposoa, Prov. Huallaga, San Martín).

- Cerro Los Cedros (distrito Saposoa, Prov. Huallaga, San Martín).

- $\quad$ Cerro Monte Unión (distrito Saposoa, Prov. Huallaga, San Martín).

- $\quad$ Israel (distrito Saposoa, Prov. Huallaga, San Martín).

- $\quad$ La Morada (distrito Saposoa, Prov. Huallaga, San Martín).

- $\quad$ Orfedón (distrito Saposoa, Prov. Huallaga, San Martín).

- Chibul (prov. Pataz, La Libertad).

- Cusungul (distrito Bambamarca, prov. Bolivar, La Libertad).

- $\quad$ Pururu (distrito Bambamarca, prov. Bolivar, La Libertad).

- Callangate (distrito Bambamarca, prov. Bolivar, La Libertad).

- Cujibamba (distrito Bambamarca, prov. Bolivar, La Libertad).

- $\quad$ El Convento (distrito Bambamarca, prov. Bolivar, La Libertad).

- $\quad$ Pakarishka (distrito Bambamarca, prov. Bolivar, La Libertad).

- Kunturmarka (dist. Bambamarca, prov. Bolivar, La Libertad). Un gran número de farallones con cuevas y abrigos rocosos que contienen mausoleos y tumbas Chachapoya en la sierra de la margen derecha del río Marañón y el bosque Nuboso Alto.

En este contexto se ha descubierto el Cerro Las Cruces, cuyas exploraciones y estudios permiten considerarlo como un enorme sitio arqueológico conformado por un complejo de edificaciones arquitectónicas (120 unidades) emplazadas en medio del bosque nuboso, el que cubre cumbres y laderas del macizo rocoso, uno de los más elevados de la margen derecha del río Guabayacu, distrito de Saposoa, provincia de Huallaga (a 3,000 m.s.n.m.).

\section{Excavaciones Arqueológicas en Cerro Las Cruces.}

«Cerro Las Cruces» es un enorme sitio arqueológico está conformado por un verdadero complejo de testimonios arquitectónicos asentados en medio del bosque 


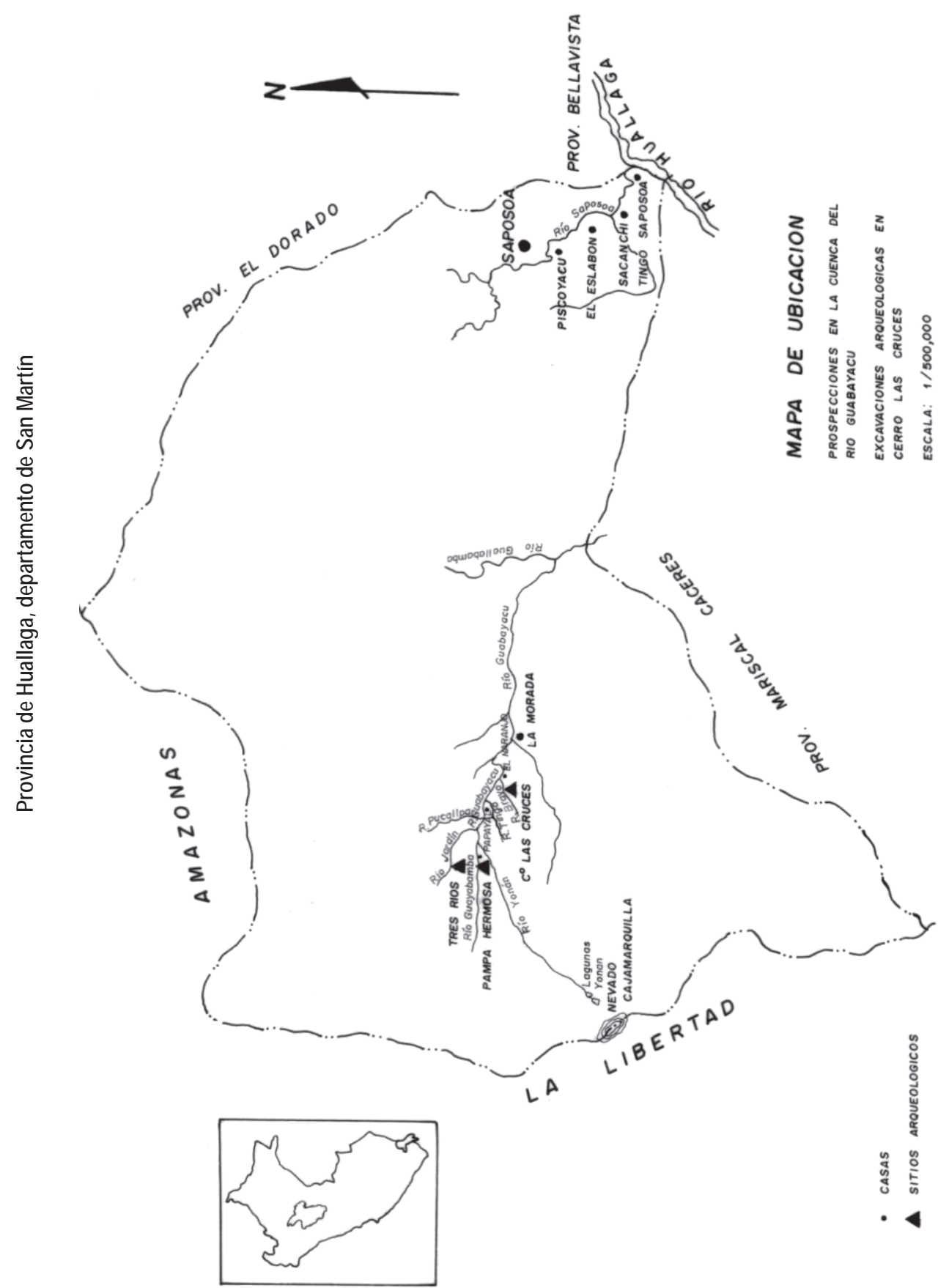


nuboso que cubre cumbres y laderas del macizo rocoso, uno de los más elevados de la margen derecha del río Guabayacu; de las prospecciones y reconocimientos realizados podemos distinguir cantidad de edificios en planta circular emplazados desde sus laderas medias hasta la cumbre alargada en dirección este-noroeste y una serie de mausoleos funerarios construidos en los farallones intermedios y altos de tales cerros.

\section{a) Área de excavaciones:}

\section{Plaza Pública de Cerro las Cruces $\quad$ RG/PPCLC/10 \\ Unidad Edificio 1}

Las excavaciones permitieron estudiar la ubicación de un conjunto de farallones de roca caliza y roca caliza-pizarrosa, por los que ascendemos hacia sus cumbres; en los tercios altos de los cerros se horadaron antiguamente abrigos rocosos para extraer las rocas con las cuales se construyeron una serie de mausoleos usando piedras y lajas planas asentadas con barro, las cuales fueron revestidas con aplanado de roca caliza molida, dejando un aspecto exterior de color blanco; sobre este enlucido, algunos mausoleos conservan la pintura blanca muraria (ejm.: los mausoleos llamados Casa Blanca) como acabados externos. Los mausoleos llevan cornisa corta ( $0.10 \mathrm{a} 0.15 \mathrm{~m}$. promedio) a base de lajas planas ( $0.5 \mathrm{~m}$ a $0.15 \mathrm{~m}$ de espesor promedio) y separan la cámara inferior de la superpuesta. Hay también mausoleos de un solo piso, pero de doble o triple cámara lateral.

En la cuenca del río Guabayacu la mayoría de los farallones tienen mausoleos; hay uno con pintura roja en morfología de media luna y que los lugareños llaman «Luna» al sitio. Algunos de estos mausoleos tienen edificaciones cuadradas pequeñas cuyas medidas promedio son de $0.40 \mathrm{~m}$. $\times 0.40 \mathrm{~m}$. y $0.50 \mathrm{~m}$. x $0.50 \mathrm{~m}$. Dentro de las oquedades de los farallones quedaban al interior las cámaras sepulcrales de morfología rectangular o cuadradas, protegidas por los rectos muros externos con esquinas a plomo. Se trata de edificaciones mortuorias construidas al pie del arranque de los farallones naturales, algunos de los cuales fueron ampliados esculpiendo la roca madre para aumentar hacia adentro los niveles constructivos de las cámaras. En el interior se colocan los paquetes funerarios preparados de la manera siguiente: preparaban tablillas de $i c h o n t a$ blanca? taraceadas en los extremos con muescas talladas en «V», las que eran insertadas en una base circular de madera $(0.20 \mathrm{~m}$ promedio de espesor) y en cuyo interior se colocaba el paquete funerario envuelto en telas, algunos de los cuales eran amarrados con soguillas enlazadas fabricadas a base de fibras vegetales.

En algunos mausoleos se encuentran canastas caladas de fibra vegetal, en cuyo interior se colocaba un cadáver, a veces de niños. Tenían pocas ofrendas asociadas de cerámica Chacha. 
En el mausoleo Casa Blanca se encuentra lanzas de chonta con medidas entre $1.90 \mathrm{~m}$. a $2.40 \mathrm{~m}$. Estas lanzas son muy pulidas y la punta agudizada y endurecida al fuego.

También se recuperan textiles rotos por los saqueadores de las tumbas: éstos son de fibra de algodón, a base de hilos delgados, color blanco y variedad de técnicas.

Del exterior de algunos de estos mausoleos hemos recuperado textiles policromos y ejemplares de cestería, indicadores de arte significativo en ambas clases de fibras. Se asocian cántaros de cerámica decorada en técnica piqueteada Chacha.

En algunos mausoleos se encuentran morteros desgraciadamente fragmentados o parcialmente golpeados.

De uno de estos mausoleos se recuperó un aríbalo (p'iuyñun, en quichua) Tawantinsuyu, decorado con el tema de helechos en franjas verticales, como es típico de la cerámica Cusco imperial.

\section{Chozo funerario Chachapuya}

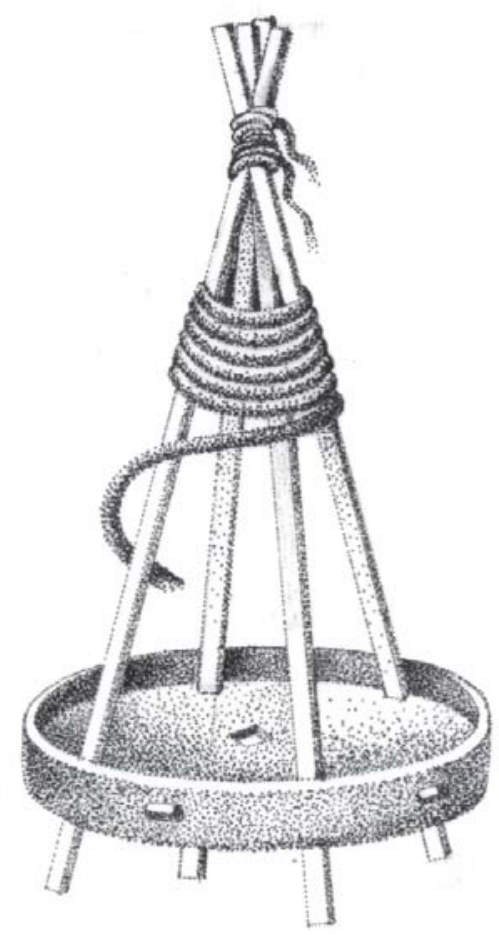

Cuenca del Río Guabayacu, ejemplar reconstruído. Código: RG/MEN/6-A

\section{b) Edificios en Planta Circular}

Continuamos el ascenso después de visitar cuatro sectores con farallones y mausoleos, hasta alcanzar la cumbre del Cerro Las Cruces. En la cumbre caminamos entre edificios circulares, los que se encuentran espaciados en próxima vecindad por ambas laderas húmedas; la mayor concentración de edificaciones está en la cumbre, casi en línea este-oeste.

Los edificios circulares están construidos asentados en la roca madre, a base de piedras amorfas pequeñas y grandes, cuyos intersticios los cubren lajas planas delgadas, todas unidas con barro. Los muros circulares se elevan directamente sobre la roca madre emergente, de cuya sección céntrica superior elévase la edificación circular hasta dos metros promedio, la que consideramos habitacional; las edificaciones circulares tienen un vano de acceso conformado por dos losas planas largas verticales de $0.50 \mathrm{~m}$. x $0.70 \mathrm{~m}$. promedio, según las dimensiones de las diferentes unidades en estudio. Otras veces, 
se construye una plataforma rectilineal, sobre la cual también se elevan edificaciones circulares con las características habitacionales anotadas.

En su conjunto, la arquitectura de la región se muestra en los ejemplos siguientes:

1. Edificios de morfología redonda aislados con basamentos circulares.

2. Conjunto de edificios circulares/plaza rectilineal con plataforma-estrado lateral.

3. Terrazas rectilineales de contención para plaza pública.

4. Basamentos-torres para vigilancia y control.

5. Edificios ornamentados con «cruces» frente a frente en la plaza pública.

6. Ornamentos: Cabezas clavas pequeñas, cruces en técnica remetida a los muros, etc.

7. Ménsulas salientes de los muros.

8. Los edificios tienen cornisas; la alzada de los muros externos, desde la base, se eleva de $2.20 \mathrm{~m}$. x $2.50 \mathrm{~m} ., 3.00 \mathrm{~m}$. x $4.00 \mathrm{~m}$., y $5.40 \mathrm{~m}$. x $6.40 \mathrm{~m}$. Las cornisas marcan una primera sección basal en la elevación de los muros externos, luego se eleva de la sección céntrica alta una segunda edificación. En las unidades arquitectónicas altas, las cornisas van en número de dos y tres hasta alcanzar, por ejemplo, los seis metros cuarenta de altura (edificios del Sector Las Torres).

9. Los vanos están ubicados en un tramo de la elevación muraría redonda de las unidades arquitectónicas construidas sobre los basamentos, consideradas habitacionales. Sus medidas varían entre $0.40 \mathrm{~m}$. y $0.80 \mathrm{~m}$. de ancho por una altura no cuantificable, porque ninguna está completa. Los árboles y arbustos, bejucos y otras plantas, con sus poderosas y gruesas raíces, han deslizado, removido, desplomado y deformado los muros, vanos y cornisas de las construcciones.

10. Hay distinta tipología arquitectónica entre los edificios de arquitectura circular y los mausoleos en planta rectilineal; sólo alguno que otro mausoleo es en planta circular.

11. Pocos mausoleos tienen vanos altos cuadrados (ventanas), como lo demuestra el sitio de Casa Blanca.

12. Plaza pública rectangular conformada por grandes muros laterales inferiores construidos en los flancos de las laderas altas del Cerro Las Cruces para dejar 
espacio de un plano superficial rodeado de edificios con ornamentación de cruces remetidas en los muros y de formulación simétrica. Se nota que las cruces van en grupos de tres en los frontis externos/ tanto de la arquitectura circular como de aquellos en planta rectilineal. En la plaza pública se encuentran ambos tipos arquitectónicos.

13. La plaza pública tiene una plataforma/estrado pétrea a sobrenivel céntrico, construido con piedras de diferentes pesos hacia el rumbo norte-noreste de ésta; se trata de una edificación baja platafórmica de contorno hemicircular, con superficie empedrada por lajas planas; lleva un respaldar murario al centro de tal plataforma, exhibiendo remate de superposición de dos alineamientos de piedras labradas superpuestas sobre muros de lajas Chacha. Hacia adelante termina tal estrado en una cornisa corta $(0.15 \mathrm{~m}$ promedio) conformada por losas grandes de filete ligeramente circulado. Al pie, en dirección sur, se presenta el espacio abierto de la plaza en una extensión de $18.60 \times 28.90$ metros y también termina en una cornisa delantera de $0.12 \mathrm{~m}$. promedio, hacia la ladera sur del cerro.

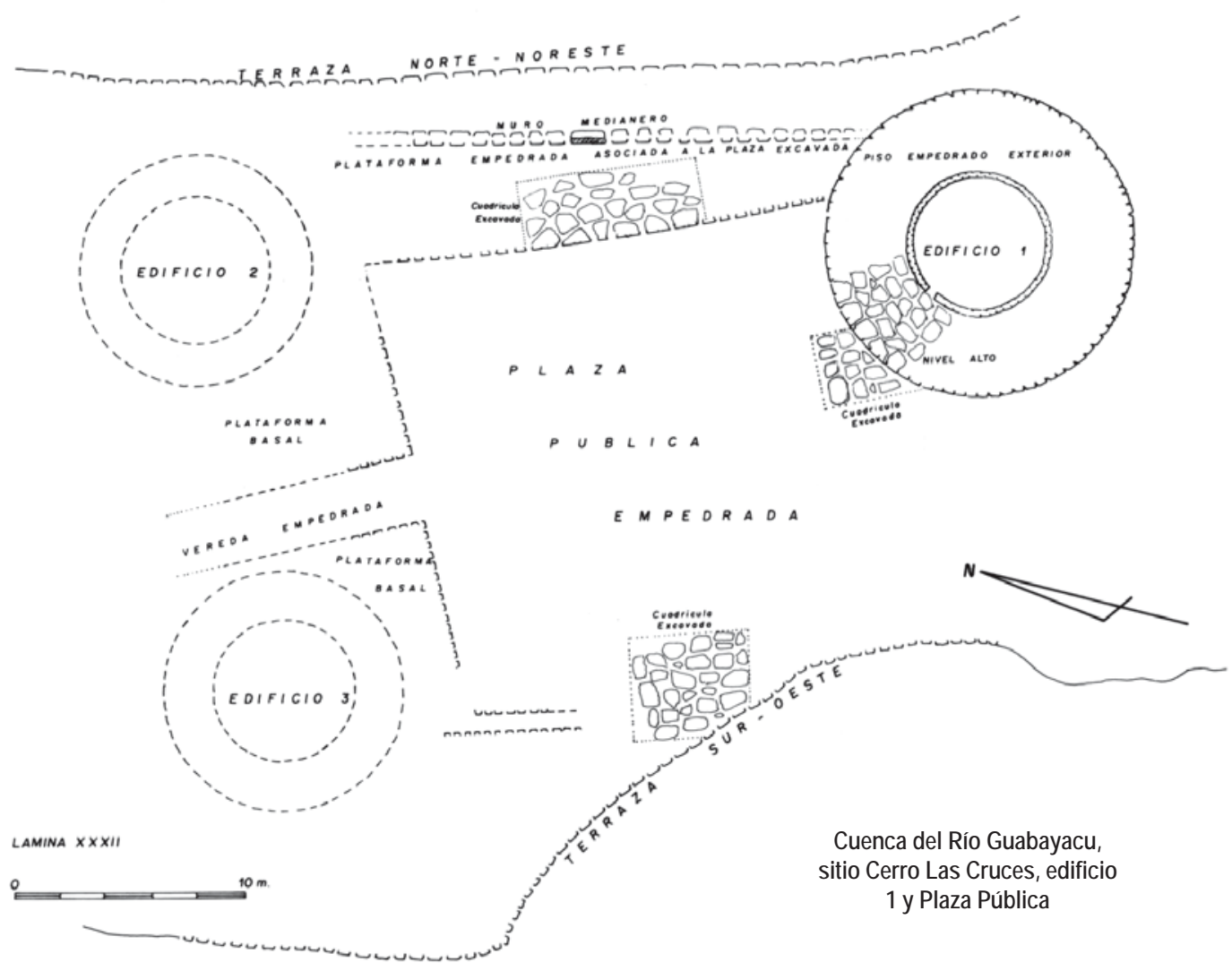


14. Hay senderos de comunicación entre los distintos sectores de edificios bajos $\mathrm{y}$ altos y entre los del mismo nivel físico.

\section{c) Las excavaciones arqueológicas.}

Se cuadriculó la Plaza Pública para iniciar los trabajos de excavación. Los trabajos fueron planteados ejecutando la cuadrículación en base a coordenadas cartesianas; las excavaciones fueron planteadas en área, pero eligiendo cuadrículasmuestreo, es decir, excavando estratégicamente cuadrículas que mostraran sus distintos sectores, sin tratar de excavar todas las cuadrículas, porque habríamos tenido que deforestar los quince grandes árboles que han crecido en su espacio físico. La exploración experimental de arriba hacia abajo tiene la siguiente secuencia de superposiciones en la Plaza Pública:

1. Capa superficial de hojas húmedas de 0.20 a $0.30 \mathrm{~m}$. promedio.

2. Capa de raíces delgadas y gruesas de 0.30 a $0.40 \mathrm{~m}$. promedio.

3. Capa de tierra-humus de aspecto negro de 0.10 a $0.15 \mathrm{~m}$. promedio.

4. En los edificios del oeste de la plaza en planta rectilineal con cruces, la tierra de los desplomes de sus esquinas que dan al pasadizo intermedio es grisamarillenta. Las esquinas de estos dos edificios se desplomaron hacia la plaza.

5. El piso de la plaza está cubierta de lajas planas asentadas con barro.

6. Debajo de las lajas, que uniformizan el piso de la plaza, encontramos muros de hasta tres terrazas subyacentes, que denotan la construcción previa de terrazas consecutivas, las que fueron ampliando la extensión de la plaza. La última extensión fue Tawantinsuvu (1,470-1,533 d.C).
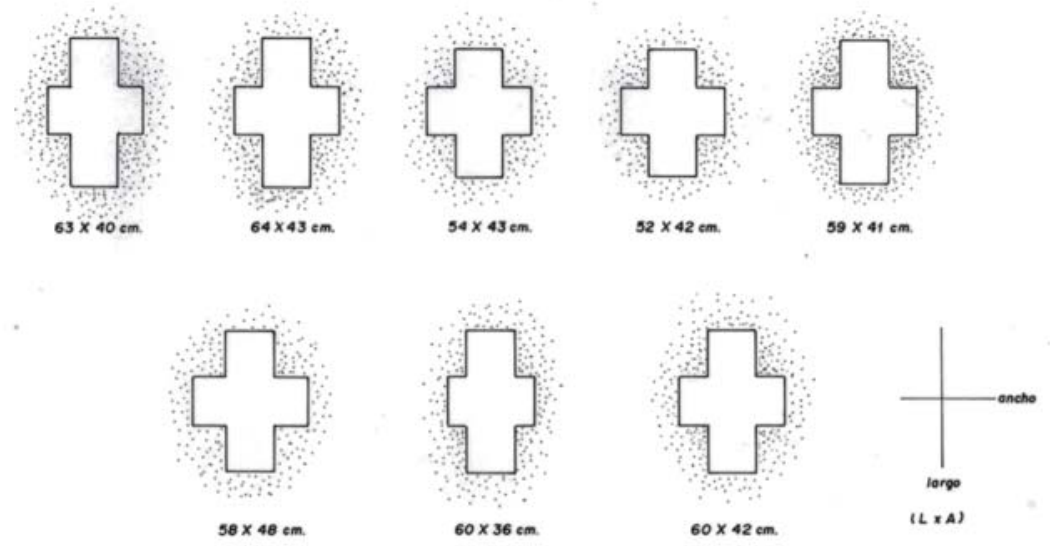

Cuenca del río Guabayacu, sitio Cerro Las Cruces-Edificio, muestra de cruces remetidas el paramento exterior. 
Trabajos en la plataforma-estrado.

a) Piedra arenisca rosada encontrada deslizada hasta el pie del estrado. Se le levanta a su sitio, en el respaldar del estrado utilizando polines y palancas de madera.

b) Medidas: $1.70 \mathrm{~m} . \times 0.75 \mathrm{~m} . \times 0.30 \mathrm{~m}$.

c) Levantamiento de la piedra labrada: sobre polines de madera ayudados por palancas de troncos y fuerza humana.

d) La piedra es una losa pulida en sus cuatro lados, de morfología rectangular; formaba parte originalmente del paramento del respaldar del estrado significativo. En este respaldar se presentan algunas piedras labradas de pesos diversos que conforman el muro señalado.

En el respaldar no se usaron piedras labradas en todo el largo del muro, sino solo en la parte central, siendo el resto completado con piedras sin labrar.

Una hipótesis es que haya sido reparada parcialmente por el Tawantinsuyu después del abandono Chacha. Grandes árboles crecen en su superficie, además de estar cubierta de espeso follaje. Sin embargo, detrás del respaldar hacia el rumbo norte descubrimos otro gran muro vertical $(2.80 \mathrm{~m}$. de alto) que aterraza a la superficie plana siendo una continuidad, detrás del respaldar, de la plataforma que da hacia la plaza. Esta superficie queda sin trabajar, para poner atención a la plaza.

Excavación de la Cuadrícula A3: de arriba hacia abajo:

1. Retirado de $0.30 \mathrm{~m}$ de hojarasca y ramas secas de superficies acumuladas con el tiempo.

2. Corte a machete de raíces gruesas, delgadas y raicillas, las que conforman una capa de $0.30 \mathrm{~m}$. de espesor promedio en esta cuadrícula.

3. Debajo de la capa 2 encontramos una pequeña capa de tierra-humus negra de $0.10 \mathrm{~m}$. promedio.

4. Quitada esta tierra-humus por decapado en toda la superficie del cuadro, apareció a nuestra vista una superficie empedrada con losas pequeñas (0.15$0.25 \mathrm{~m}$. promedio de superficie $\times 0.10-0.12 \mathrm{~m}$. promedio de espesor), las que originalmente debieron haber sido colocadas en forma uniforme, pero al presente se encuentran desniveladas por el crecimiento de las gruesas raíces de los árboles de 15, 20 ó 30 metros de altura que crecen en la plaza. Los árboles quedan in situ. 
5. Se limpia la tierra de excavación y restos de raíces barriendo todo al final con escoba de mano; un metro de extensión lateral fue medido junto al muro del edificio de Las Cruces, perfil este, para excavar en profundidad debajo del piso de piedras y poder examinar el basamento arquitectónico de la unidad $\mathrm{N}^{\circ} 1$ en excavación por Miguel Cornejo y cuyo protocolo excavatorio vendrá más adelante.

6. Como la cuadrícula tiene $4.00 \times 4.00 \mathrm{~m}$., el metro a excavar en profundidad se mide junto al edificio. La excavación desciende quitando tierra limpia, con grumos pequeños y raíces delgadas de bejucos, hasta la profundidad de 0.60 a $0.65 \mathrm{~m}$. promedio, al no ser uniforme el subsuelo debido a que aflora la roca madre del cerro a esta profundidad.

7. No se recupera material arqueológico porque no se encontró en ninguna de las capas salvo el piso superficial de piedras anotado.

8. El cimiento del edificio circular de las cruces descansa directamente sobre la roca madre a sólo dos hiladas de piedra en el subsuelo $(0.35 \mathrm{~m}$. promedio de profundidad), de tal manera que de frente comienza el sobrecimiento hasta la cornisa, que se ubica sobre el tercio medio de la alzada del muro externo frente al lado este de la Plaza Pública. El segundo edificio superpuesto arranca del centro alto de la cimentación circular con su vano hacia el oeste.

9. El edificio circular este expone once cruces en su base externa que da frente a la plaza pública. Han sido medidas tres cruces del lado izquierdo externo, flanco oeste; las medidas interiores de las cruces están consignadas en los dibujos del diario de campo. Sin embargo, consignamos la medida total de la circunferencia del basamento del edificio de las once cruces: $45.40 \mathrm{~m}$.; altura $3.15 \mathrm{~m}$.; cornisa: $0.30 \mathrm{~m}$. promedio.

10. No se registró material arqueológico alguno.

Excavación Cuadrícula C1: La Plataforma / Estrado con respaldar.

1. Superficie con follaje, árboles, raíces gruesas y delgadas y mucha hojarasca.

2. Tala con machete del follaje arbustivo, bejucos y cuatro árboles pequeños de 3.00 y 4.00 metros de altura. Retiro de una capa de $0.40 \mathrm{~m}$ de hojarasca.

3. Corte con machete de una capa de raíces y raicillas de color marrón humítico denso de 0.30 a $0.35 \mathrm{~m}$.

4. Capa de tierra negra de $0.12 \mathrm{~m}$. de espesor que ocurre directamente sobre la capa del piso empedrado, el que es descubierto debajo de ella. Analizada esta capa de tierra negra, establecimos que se había formado en proceso de 
percolación por filtración del agua de lluvia desde la superficie a través de la hojarasca y capa de raíces, para extenderse en morfología terrosa sobre la superficie del piso de piedras descubierto a $0.80 \mathrm{~m}$. promedio de profundidad.

5. El piso de piedras no es totalmente plano, pues tiene un ligero declive, muy suave, quizás funcional para que el agua se deslice, igual que todo el empedrado de la plaza, cuyo declive muy suave es de norte a sur. Las piedras del piso son de tamaños distintos, entre pequeñas y medianas, todas planas y de contornos irregulares. Sólo las losas delanteras, que forman una cornisa voladiza $(0.15 \mathrm{~m}$. promedio, porque no es uniforme), son grandes; la roca plana central por ejemplo mide $1.10 \mathrm{~m} . \times 1.60 \mathrm{~m}$. x $0.40 \mathrm{~m}$. promedio, debido a que no se sabe cómo es hacia adentro, en el subsuelo; las medidas proceden de los lados que se ven: superficie y lado sur de la piedra. Otras piedras de menores dimensiones conforman la delantera terminal ligeramente hemicircular platafórmica del estrado (concepto funcional) de esta plataforma sobre elevada en relación con la plaza pública.

6. Al final de la excavación y al rincón céntrico de la plataforma, parte central de la cuadrícula de excavación, se cobró una piedra pequeña con un cinturón trabajado en técnica frotada, como para amarrar una cuerda delgada; se trataría de una boleadora; un fragmento de cerámica llana también se encontró en el nivel superficial del piso de lajas.

7. Se barrió y limpió con escoba de mano el piso.

Excavación de la Cuadrícula D3:

Esta cuadrícula está programada para excavarse en el lado oeste de la Plaza Pública, donde dos edificios en planta cuadrada exhiben tres cruces cada uno y el segundo piso, desplomado hasta su esquina sur.

La excavación registró los siguientes pasos:

1. Superficie irregular con amontonamiento de hojarasca y raíces encima de piedras caídas y raicillas en champa.

2. Corte de champas de raíces y raicillas hasta una capa de 0.20 a $0.25 \mathrm{~m}$. de espesor.

3. Capa de piedras de derrumbe con entretejido de raíces de grandes árboles; retirada de las piedras amorfas, otras parcialmente labradas y algunas pocas piedras planas labradas; se conservan amontonadas en cuadros.

4. Debajo de las piedras desplomadas (1.20 m. de derrumbe), descubrimos 0.10 $\mathrm{m}$. promedio de barro negro escurrido por percolación al fondo. Excavada a 
badilejo esta capa de tierra negra y raicillas, apareció el piso de lajas como en el resto de la plaza. Esta cuadrícula deja al descubierto, además del piso enlajado, los paramentos de la sección baja o basamento de esquina rectilineal de los edificios en planta cuadrada, mostrando sus «tres cruces» cada uno.

5. Entre las dos edificaciones de este lado oeste que avanza hasta el suroeste de la plaza, encontramos un pasaje entrambos edificios de $1.50 \mathrm{~m}$ de ancho.

6. Entre las piedras caídas recuperamos dos piedras talladas, las cuales se trabajaron al sistema de caja y espiga. Recuperamos una bolsa con fragmentos de cerámica llana durante los trabajos.

Excavación de las Cuadrículas D7-E7.

1. Estas se ubican en la esquina suroeste de la Plaza Pública.

2. Se excavan dos cuadrículas consecutivas.

3. Capa de hojarasca, raíces y champas de raicillas de $0.20 \mathrm{~m}$. de espesor.

4. Capa de champas densas de raicillas humíticas de color marrón de $0.30 \mathrm{~m}$. de espesor.

5. Delgada capa de tierra negra percolada de $0.05 \mathrm{~m}$. de espesor.

6. Quitado a badilejo de la delgada capa de tierra negra, debajo de la cual va apareciendo el empedrado de lajas planas colocadas en forma similar que en las otras cuadrículas descritas para la plaza pública.

7. El piso de lajas planas avanza hasta cubrir la primera plataforma sur con su cornisa. Su muro externo se aprecia desde el exterior.

8. Medidas de los componentes de la Plaza Pública: Muro lateral: altura $3.50 \mathrm{~m}$. promedio al lado sur de la plaza.

Muro lateral sur-oeste de la plaza: Altura $4.00 \mathrm{~m}$. de elevación hasta la cornisa. Este muro permitió a los Chacha nivelar esta ladera alta para ser base de la construcción del edificio oeste rectilineal con tres cruces, cuyo perfil sur parcialmente desplomado está orientado a este lado, el que presenta $4.20 \mathrm{~m}$. de piso superficial + $0.15 \mathrm{~m}$. de cornisa (promedio). Muro lateral norte de la plaza: Altura $2.80 \mathrm{~m}$. promedio.

La plaza tiene cinco plataformas +1 posterior:

- $\quad$ Plataforma alta del lado suroeste: piso sur 1:1.85 m. ancho de superficie +0.12 m. promedio de ancho de cornisa. 
- 2da. Plataforma: Piso 2: ancho de superficie de $2.05 \mathrm{~m}$.

- 3ra. Plataforma: Piso 3: ancho de superficie de $5.00 \mathrm{~m}$.

- 4ta. Plataforma: Piso 4: ancho de superficie de $13.70 \mathrm{~m}$.

- 5ta. Plataforma: Piso 5: ancho de superficie de $4.05 \mathrm{~m}$. (superficie de la plataforma/estrado a sobrenivel).

- 6ta. Plataforma: Piso 6: ancho de superficie de $8.80 \mathrm{~m}$. (parte posterior del respaldar pétreo no excavado).

- $\quad$ Ancho de la Plaza este-oeste: $20 \mathrm{~m}$.

Excavaciones en la Unidad $N^{\circ} 1$ de Cerro Las Cruces.

La Unidad $\mathrm{N}^{\circ} 1$ es un gran edificio circular con 5.40 metros de diámetro interno y 14.71 metros en su diámetro externo, correspondiente a la plataforma circular del segundo piso. Para los efectos del registro de excavación el edificio fue dividido en cuatro cuadrículas siguiendo la orientación de las agujas del reloj.

Empezó el trabajo con la deforestación de los arbustos y follaje crecidos en el interior del segundo piso. Despejado el follaje y los arbustos, encontramos que el muro curvo corrido se había desplomado al interior, por lo que iniciamos el trabajo de extraer las piedras a mano, una por una:

Cuadrícula 1: esta cuadrícula estaba completamente cubierta por piedras del desplome lateral del muro corrido; tiene las siguientes dimensiones $2.43 \mathrm{~m}$. x 2.09 metros; se retiran las piedras caídas y procedimos a excavar el primer nivel conformado por tierra de textura color marrón rojiza y textura compacta.

Cuadrícula 2: tiene la extensión de $2.09 \mathrm{~m}$. x 3.07 m.; el paramento interior está inclinado hacia adentro como técnica constructiva, pues conforme el muro corrido circular ganaba altura, éste era técnicamente angostado para sostener la cubierta cónica. Entre las piedras caídas, las raíces de los árboles y bejucos se han introducido en el muro corrido y el piso; conforme se retiró los materiales de desplome, aparece la tierra color marrón rojiza grumosa muy húmeda, similar a la de la cuadrícula 1.

Se recuperan fragmentos de cerámica Chacha, resaltando un fragmento de borde decorado en técnica apliqué en morfología serpentiforme, interior negro reducido, exterior rojo pulido y borde engrosado. También se recupera material orgánico asociado (un tipo de semillas de cedro, achira y castaña). 


\section{Amazonía Peruana}

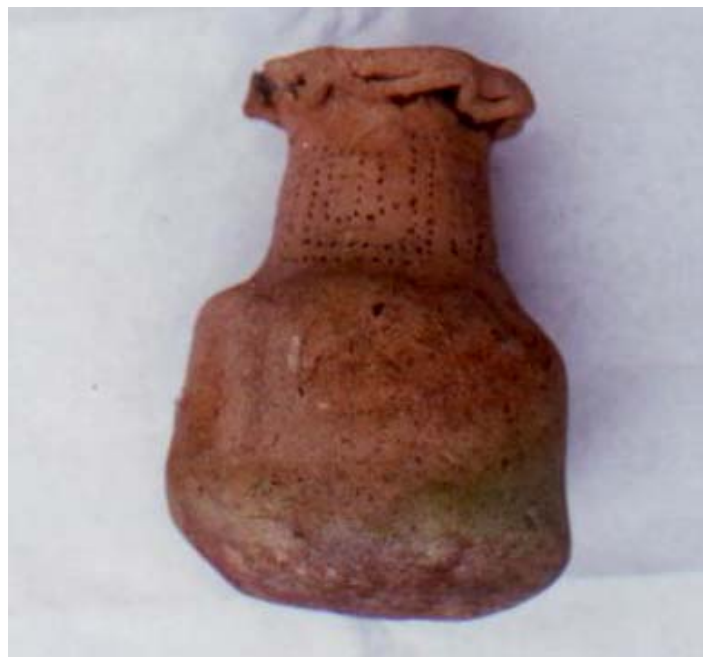

Figura.

Ceramio de tipología Chacha procedente de Cerro Las Cruces.

\section{Vantaro Chachapuya}

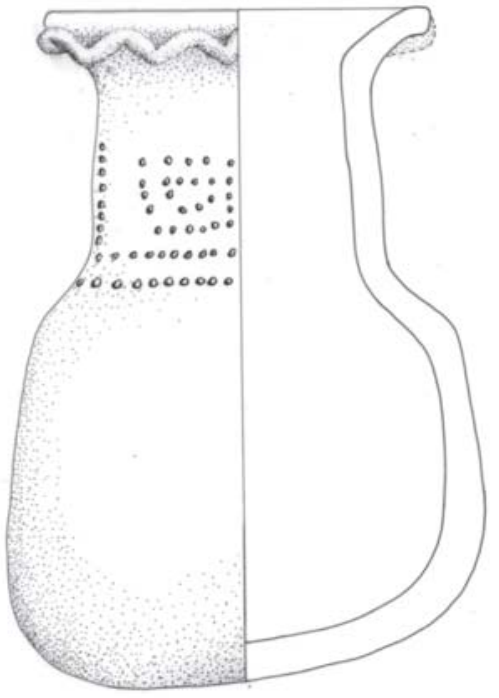

Figura.

Cuenca del río Guabayacu

Sitio Cerro las Cruces-sector Las Torres

Código: RG/CLC/ST 
Según los procedimientos técnicos colectamos cinco fragmentos de huesos zoomorfos, algunos carbones vegetales, dos artefactos líticos y 100 gramos de tierra rojiza para análisis químico.

Con la finalidad de controlar y verificar la estratificación se excavó un pozo de control $(0.50 \times 0.50 \mathrm{~m}$.), hacia el lado sur de la cuadrícula, registrándose las siguientes capas:

a) $\quad 0.70$ m.; color de la tierra: 7.5 y R 8/4 marrón oscuro.

b) $\quad 0.69$ m.; color de la tierra: 10 y R 3/4 marrón rojiza.

c) $\quad 0.67 \mathrm{~m}$.; color de la tierra: 10 y R 8/1 blanquecina.

d) $\quad 0.69$ m.; color de la tierra: 10 y R 8/6 amarillenta.

Excavamos mediante niveles de $0.10 \mathrm{~m}$. para mejor control en el descenso excavatorio, estableciendo al final cuatro capas del derrumbe al interior de la unidad.

Cuadrícula 3: en esta cuadrícula, que ocupa posición relacionada con el eje central de la cuadrículación, se descubre el vano conservando sus jambas laterales al nivel de su base; al retirar las piedras caídas comprobamos su orientación de $40^{\circ}$ al noroeste $(\mathrm{NW})$. Este vano tiene $0.90 \mathrm{~m}$. de altura y $0.80 \mathrm{~m}$. de ancho conservados, al que se le asocia una laja de $0.90 \mathrm{~m}$ de largo, sugiriendo un dintel; en el nivel del piso terminado presenta lajas planas de $0.55 \mathrm{~m} . \times 0.40 \mathrm{~m}$. fuertemente asentadas con barro marrón rojizo. Entre los hallazgos figuran huesos zoomorfos, una segunda cabeza clava suelta entre las piedras de desplome $(0.25 \mathrm{~m}$. de largo x $0.14 \mathrm{~m}$. de alto) y factura bastante tosca.

Cuadrícula 4: hacia el paramento norte interior se ubica ésta; retiramos las piedras que estaban caídas en forma caótica, se hizo el dibujo de planta respectivo y excavamos la tierra marrón rojiza; durante estos trabajos se descubrió una cabeza clava en piedra arenisca; representa un rostro humano y se le reconoce de cultura Chacha: mide $0.10 \mathrm{~m}$. de largo x $0.09 \mathrm{~m}$. de altura; está ligeramente erosionada, sus dos ojos están completos, la nariz es larga y protuberante, su boca está cerrada y presenta un faltante en el lado izquierdo de la cabeza.

En este cuadrante ubicamos una piedra tallada $(0.37 \mathrm{~m}$. de largo), dividida en tres secciones: la primera de $0.38 \mathrm{~m}$., la segunda tiene $0.53 \mathrm{~m}$., $0.10 \mathrm{~m}$. la tercera y $0.20 \mathrm{~m}$. de ancho máximo. Está trabajada con incisiones que dividen cada parte y una incisión vertical separadora en dos mitades. También se recuperan dos astas de cérvido, fragmentos alfareros, huesos rotos y algunos carbones. Se la excavó hasta llegar al piso terminado con lajas.

Cuadrícula 5: se ubica hacia el lado extremo del interior excavado; la finalidad técnica fue la de encontrar factores de relación y continuidad de la edificación del 
segundo nivel, con el piso externo hasta la cornisa y su basamento circular ornamentado con cruces.

Por las prospecciones y reconocimientos arqueológicos ejecutados se ha descubierto cantidad de edificios en planta circular de distintas dimensiones, asentados desde sus laderas medias hasta las tres cumbres que posee alargadas en dirección este-noroeste; en la parte baja se notan andenerías cubiertas por el bosque con muros de $2.00 \mathrm{~m}$. a $3.00 \mathrm{~m}$. de altura. Los edificios circulares están construidos asentados en la roca madre, a base de piedras amorfas pequeñas y grandes, cuyos intersticios los cubren lajas planas delgadas todas unidas con barro. Los muros circulares se elevan directamente sobre la roca madre emergente, de cuya sección céntrica superior elévase la edificación circular hasta dos metros promedio, la que consideramos habitacional; las edificaciones circulares tienen una puerta de acceso conformadas por dos losas planas largas verticales, según las dimensiones de las diferentes unidades observadas.

Otras veces construyeron una plataforma rectilineal de $3.00 \mathrm{~m}$. o $4.00 \mathrm{~m}$. de alto sobre las cuales se elevan edificaciones circulares importantes alcanzando altura total de $7.00 \mathrm{~m}$. a $10.00 \mathrm{~m}$. indistintamente.

En la cumbre del Cerro Las Cruces se ha reseñado el descubrimiento de una plaza pública con el piso empedrado, rodeada de edificios circulares de dos pisos, algunos decorados con cruces y a la cual llegan caminos de las distintas direcciones, configurando un centro ceremonial y sociopolítico principal del gran sitio. Consideramos, por esto, que Cerro Las Cruces es el principal sitio arqueológico de la cuenca del río Guabayacu.

También se ha explorado al pie de los farallones naturales que configuran distintos sectores del cerro. Se ha descubierto una serie de mausoleos funerarios, distribuidos en ambas laderas, donde se han horadado repisas rocosas para ampliar los agujeros naturales hacia adentro, logrando mayor espacio funerario; por fuera han edificado en planta cuadrada o rectangular y mixtilíneas verdaderas casas funerarias, enlucidas y pintadas de blanco o color rojo indistintamente, tanto parietal como representando motivos figurativos antropomorfos (siluetas humanas) o diseños astrales y/o geométricos (luna llena, sol, círculos, círculos concéntricos, espirales, espirales dobles, grecas, etc.).

Los mausoleos se construyeron usando piedras y lajas planas asentadas con barro, las cuales fueron revestidas con aplanados de roca caliza molida, dejando así un aspecto exterior de color-blanco; los más importantes miden 3.00 × $2.50 \mathrm{~m}$., llevan cornisa corta $(0.10 \mathrm{~m}$. a $0.15 \mathrm{~m}$. promedio) a base de lajas planas las que separan la cámara inferior de otra superpuesta, lo cual quiere decir que son de dos pisos y hasta tres pisos mediante entablados de madera. Hay también mausoleos de un solo piso, pero de doble o triple cámara funeraria lateral, en los cuales encontramos 
dos o tres cadáveres colocados en los pisos asociados a ajuar funerario: canastas caladas de fibra vegetal, cerámica Chachapoya; en las tumbas importantes también se encuentra cerámica inca, lanzas en chonta pulida, textiles multicolores en fibra de algodón, maderas labradas y otros.

\section{d) Los Mausoleos funerarios}

Están distribuidos entre la margen derecha del río Guabayacu y la margen derecha del río Bravo; las exploraciones de ambas laderas del cerro han permitido ubicar los emplazamientos de tales testimonios en la base y alzada natural de los farallones rocosos, los cuales muestran trabajo de horadación de las repisas rocosas para ampliar los agujeros naturales, logrando mayor espacio funerario hacia adentro, construyendo afuera edificaciones en planta cuadrada rectangular o mixtilíneas, normalmente adaptadas a las formas de la roca madre.

Esas edificaciones funerarias fueron enlucidas, pintadas de blanco o rojo indistintamente, tanto parietal como representando motivos figurativos, antropomorfos (siluetas humanas) o diseños astrales y figurativos (luna llena, media luna, sol, círculos, círculos concéntricos, roleos, roleos dobles, etc.).

Se han registrado los siguientes mausoleos funerarios, de cuyos derredores se ha recuperado materiales arqueológicos disturbados, rotos o depredados, encontrados afuera de las matrices originarias; los mausoleos registrados del complejo Cerro Las Cruces son los siguientes:

\section{Sitio}

1. Mausoleos del Guabayacu

2. Mausoleos Puente Oroya A

3. Mausoleos Puente Oroya B

4. Mausoleos de las Grecas

5. Mausoleos de los Monos

6. Mausoleo del Naranjo A

7. Mausoleo del Naranjo B

8. Mausoleos Casa Blanca A

9. Mausoleos Casa Blanca B

10. Cerro las Cruces Sector Las Torres

\section{Código}

RG/MG/1
RG/MPO/2-A
RG/MPO/3-A
RG/MLG/4
RG/MLM/5
RG/MEN/6-A
RG/MEN/7-B
RG/MCB/8-A
RG/MCB/9-B
RG/CLC/ST

RG/MG/1

$\mathrm{RG} / \mathrm{MPO} / 2-\mathrm{A}$

$\mathrm{RG} / \mathrm{MPO} / 3-\mathrm{A}$

$\mathrm{RG} / \mathrm{MLG} / 4$

RG/MLM/5

RG/MEN/6-A

RG/MEN/7-B

$\mathrm{RG} / \mathrm{MCB} / 8-\mathrm{A}$

$\mathrm{RG} / \mathrm{CLC} / \mathrm{ST}$

Último sector más alto explorado del Cerro Las Cruces, donde se descubrió la torre de tres pisos y $5.60 \mathrm{~m}$. de alto (RG/CLC/ST), cubierto de vegetación como los otros edificios del gran sitio.

Cerramos las excavaciones en Cerro Las Cruces el día 8-08-2001, levantamos el campamento temporal de la ladera sur y trasladamos todo al campamento base El Naranjo. 
El campamento del Naranjo, a su vez, fue levantado el 11-08-2001. El mismo día arribamos, de regreso, a Pampa Hermosa. Aquí trabajamos dos días, para explorar las cercanías de los Tres Ríos, levantar los planos del sitio Tawantinsuyu de Pampa Hermosa y terminar su descripción. Datos consignados en este informe.

Las exploraciones adicionales permitieron descubrir un nuevo Mausoleo en la margen izquierda del río Guabayacu: el Mausoleo de los Triángulos. Se ubica a una hora de Pampa Hermosa y ascendiendo la ladera izquierda.

El mausoleo está edificado en tres niveles; el primer nivel mide 0.70 m y está adosado a la roca madre; está construido con lajas de piedra pizarra y su ubicación es de: Latitud Sur 659'28", Longitud Oeste 77³9'87"y Altitud 2,600 m.s.n.m. murarlo.

El primer nivel está separado por una cornisa que sobresale $0.15 \mathrm{~m}$. del perfil
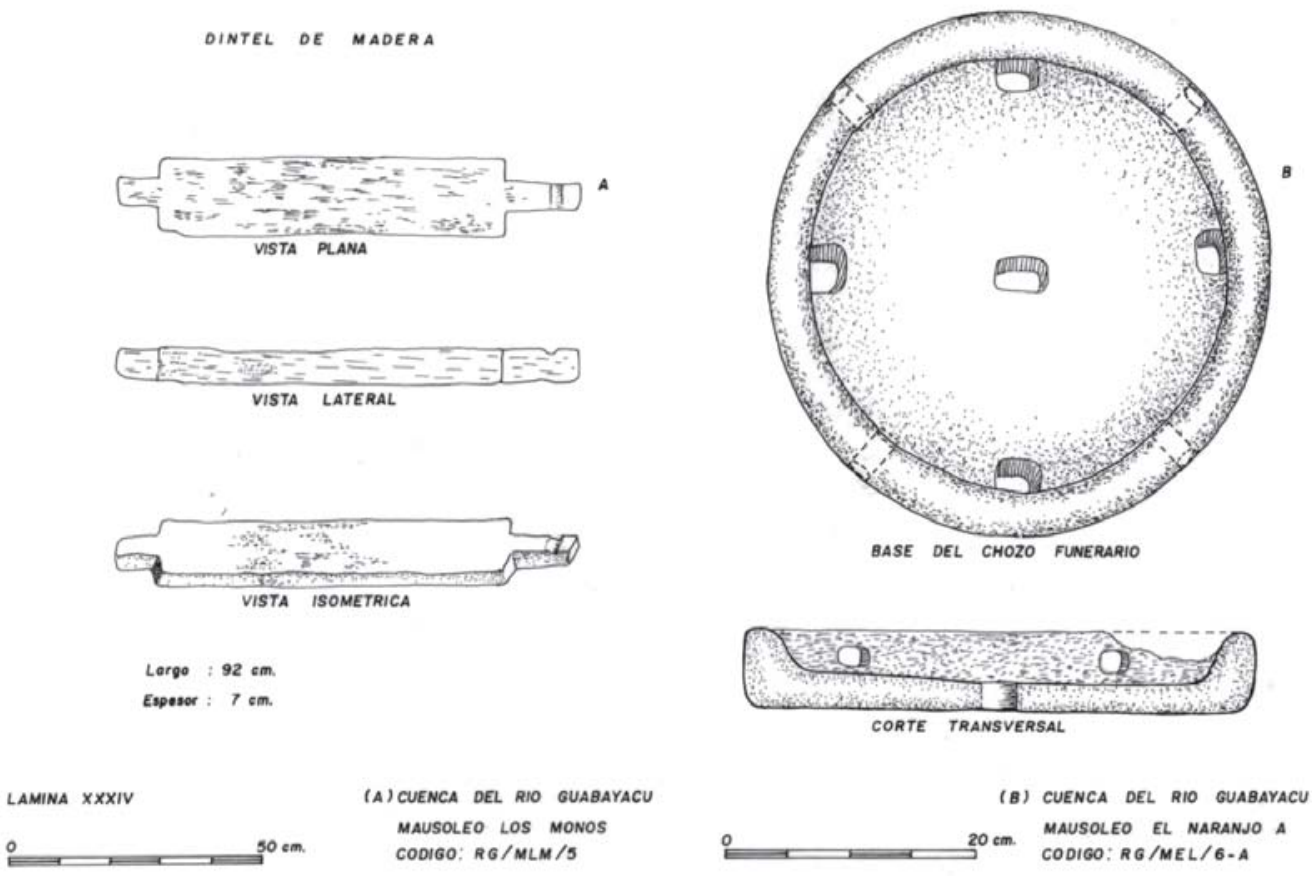

El segundo nivel mide $1.67 \mathrm{~m}$. y está decorado con siete cruces remetidas en el muro o en bajo-relieve; la primera cruz mide $0.23 \mathrm{~m}$. $\times 0.25 \mathrm{~m}$.; la segunda cruz mide $0.23 \mathrm{~m}$. $\times 0.20 \mathrm{~m}$.; la tercera mide $0.29 \mathrm{~m}$. $\times 0.30 \mathrm{~m}$.; la cuarta cruz mide $0.30 \mathrm{~m}$. x $0.27,5 \mathrm{~m}$.; la quinta cruz mide $0.33 \mathrm{~m}$. $x 0.27 \mathrm{~m}$.; la sexta cruz mide $0.28 \mathrm{~m}$. $\times 0.30 \mathrm{~m}$. y la séptima cruz mide $0.29 \mathrm{~m}$. x $0.24 \mathrm{~m}$. Estas cruces están ligeramente alineadas horizontalmente. 
El tercer nivel mide de alto $1.00 \mathrm{~m}$ y presenta ornamentación en zig-zag, con dos bandas decorativas; en su sección frontal se encuentran los dos únicos vanos: el primer vano que se ubica en el lado izquierdo mide $0.94 \mathrm{~m}$. $\times 0.52 \mathrm{~m}$. edificado con lajas planas laterales y tiene dintel superior; el segundo nivel mide $0.89 \mathrm{~m}$. $\times 0.53 \mathrm{~m}$.; las piedras conformantes del aparejo murario han sido enlucidas. Sobre las dos bandas de zig-zag que están pintadas de rojo se ubican cinco cruces en bajo relieve.

Hacia el lado superior derecho se ha situado una cabeza clava; la altura total del edificio es de $5.70 \mathrm{~m}$. de alto; en total el mausoleo tiene trece cruces, ya que una cruz ha sido colocada en una esquina externa, pero siguiendo la línea decorativa.

El mausoleo está orientado $30^{\circ}$ al NE. El mausoleo también tiene pintura mural con dos siluetas antropomorfas danzantes, con piernas flexionadas; los elementos que conforman el zig-zag miden $0.23 \mathrm{~m} . \times 0.20 \mathrm{~m}$.

El mausoleo tiene nueve tablones en la cubierta superior y en la parte interna tiene una pared divisoria. En el mismo farallón existen tres bases de igual número de mausoleos de menor tamaño completamente desplomados.

\section{Discusión Histórico-Social. Los estudios ecosistémicos y la evidencia etnográfica.}

El Bosque Nuboso Alto es una formación orogénica intrincada y compleja montañosa, conformada por quebradas de variada verticalidad, lomas bajas y lomadas, laderas en talud, márgenes bajas de los ríos, valles cortos y pasos bajos, todos cubiertos por montes, árboles y vegetación variada. Las características geomorfológicas de sus panoramas y paisajes son en « $\mathrm{V}$ », por tanto, remiten a geomorfologías jóvenes y de floresta húmeda. Numerosas cuencas torrenciales de diferentes dimensiones funcionan durante las lluvias para entallar profundamente las vertientes, formando fondos profundos y estrechos, verdaderas gargantas acuíferas permanentes.

Los cañones fluviales montuosos han sido esculpidos geoclimáticamente en rocas calcáreas, areniscas y depósitos aluvionales. Las vertientes arcillosas, como las del río Guabayacu, al estar recubiertas de vegetación, presentan procesos de solifluxión y deslizamientos, cuyas erosiones e inundaciones de arriba hacia abajo acumulan capas de limo restituyentes de la fertilidad de las tierras.

Numerosas cuencas fluviales mayores, menores y pequeñas conforman redes de ríos que discurren en la dirección de las quebradas, entre los cerros boscosos laterales y las confluencias de tales ríos, como ocurre en el thalweg donde se forma el río Guabayacu. Las aguas se deslizan a profundidad normal y a velocidad pasable a cabalgadura; las orillas de materiales rocosos, protegidas por raíces y troncos de 
grandes árboles (20 á 30 metros de altura promedio), permiten que las márgenes no se inunden, salvo durante las grandes y periódicas precipitaciones pluviales. La alta pluviosidad y la permanente erosión de los macizos rocosos determinan que los árboles y vegetales en general crezcan y se desarrollen hasta los acantilados fluviales; pero en ciertos niveles de altitud las partes altas de los cerros montuosos se muestran carentes de vegetación arbórea y arbustiva, constituyendo los farallones rocosos, donde las culturas oriundas construyeron numerosos mausoleos y tumbas menores y depusieron los cadáveres de sus ancestros protegidos de las lluvias y humedad.

En un ecosistema como el Bosque Nuboso Alto de tales características geofísicas, se establecen las interrelaciones entre los grupos humanos formando sociedades y sus correspondientes medioambientes. El medioambiente y el hombre conforman el contexto de la ecología humana. El concepto fundamental, entonces, es el ecosistema humano como complejo múltiple dinámico de interrelación e interacción ambiental y sociocultural. Tal interdependencia entre los indicadores medioambientales y culturales permite abordar variables sociales interactivas. El bosque posee la cobertura abiótica, vegetales y la fauna, donde se autogeneran los factores de subsistencia natural; es decir, los recursos naturales, a los que se suma la acción humana, construyendo los sistemas adaptativos en que las variables humanas son consideradas como el factor más importante del sistema dinámico naturaleza/ hombre. Así, el contexto para la arqueología de selva en general implica una trama espacio-temporal cuya dimensión fundamental la integran el entorno, las subsistencias o dieta, los artefactos y objetos y el pensamiento autóctono. El contexto sociocultural para la selva se aplica entonces a un solo artefacto conectado a su medio ambiente como a un sinnúmero de sitios arqueológicos de relativa vecindad. Por tanto, la arqueología espacial enfoca la trama contextual de la interrelación entre medio ambiente y cultura al interior de un yacimiento, lo mismo que las interconexiones entre distintos sitios.

Los objetivos alcanzables de nuestro proyecto, por ejemplo, son operar con los sistemas socioeconómicos de selva nubosa alta, tal como se cumplen en los patrones de asentamiento y las actividades de subsistencia. Por ejemplo, la ocupación de las cumbres de los cerros del bosque nuboso alto permitió a la gente ocupación permanente durante siglos, mayor que en la selva baja tropical. Dentro de este ecosistema humano, las sociedades arqueológicas desarrollaron variadas interrelaciones interespaciales e interacciones económicas y sociales que funcionan entrelazadas adaptativamente.

Por último, en esta teorización, la variabilidad ambiental y la mayor cantidad poblacional permanente producirán transformaciones ecosistémicas, lo cual afecta del modo que señalen los datos empíricos, a la demografía, los recursos subsistenciales, al patrón de asentamiento e incluso a las relaciones sociales establecidas. La adaptación al bosque nuboso alto debe entenderse como una 
respuesta social de supervivencia y establecimiento de vida activa permanente, así como la adaptabilidad es comprendida en términos de la capacidad de cohesión intrínseca del sistema cultural, los que funcionan conjuntamente como un sistema de ajuste in-extenso del propio sistema sociocultural. La complejidad, interacción y estabilidad ecosistémica y cultural propician, a su vez, explicar la estabilidad multigeneracional a través de varios siglos para los asentamientos de la cuenca del río Guabayacu, en las diversas interrelaciones sistémicas y su distribución geográfica de próxima vecindad. La dinámica del enfoque procesual permite explicar los componentes y la morfología de los asentamientos medioambientales, sistema donde se generan y cumplen las interacciones económico-sociales y culturales de la gente al interior de los respectivos patrones de asentamiento. La persistencia de la ocupación humana geoambiental se comprende analizando el desenvolvimiento cognitivo del comportamiento intencional de los individuos y grupos humanos activos, los que desarrollan capacidades energéticas intra-sitio para adecuarse a los recursos disponibles, transformarlos, utilizarlos, inventar técnicas orientadas a la producción alimentaria y de instrumentos, artefactos y objetos de uso colectivo, que, a su vez, generarán nuevas opciones de acumulación y avance en sentidos diversificados del colectivo social.

En cuanto a los recursos naturales del bosque nuboso alto, éstos son el conjunto de plantas (arqueobotánica) y animales (arqueozoología), sobre los que impactaron las poblaciones humanas para su cobija y alimentación. Los alimentos vegetales (frutos, raíces, rizomas y bulbos), árboles y ramas (cubiertas) y las fibras no comestibles con las que se fabrican (sogas, estambres, canastas, bolsas, prendas de vestir, tocados de cabeza, sandalias, adornos corporales, etc.), se encuentran en el ramaje de los árboles, nivel del suelo, subsuelo y a veces en los medios acuáticos. Las excavaciones arqueológicas han permitido comprobar que la gente aprovechó y utilizó los recursos vegetales y animales al máximo, desarrolló cultígenos y amplió sus fronteras agrícolas mediante andenes y terrazas, arquitectura rural que modifica culturalmente las laderas naturales de la región. Los cultivos tienen la propiedad de incrementar la producción natural hacia la productividad cultural intensiva. En el estado actual de los estudios no es posible adelantar datos sobre domesticación de animales mamíferos y avifauna o crianza en cautiverio. Sólo se da cuenta del hallazgo de huesos de fauna local, y en el caso de huesos de camélidos se asume factores de intercambio faunístico con las punas interandinas inmediatas. Por supuesto, las rutas de dispersión e intercambio, modificaciones adaptativas y presencia o ausencia de los materiales evidentes (datos) resultantes de las actividades de agricultura o crianza de animales, son fundamentales para localizar las áreas iniciales de domesticación primaria o secundaria y para identificar las regiones de contactos culturales o de intercambio selectivo o preferente.

El individuo y los grupos humanos en todos los tiempos, además de recolectores y cultivadores en el bosque montano, también funcionan como eficaces 
cazadores y grandes conocedores de los abrevaderos, tierras pantanosas y márgenes de los ríos, lagunas y lagos, como zonas de convergencia faunística. Los cazadores del bosque nuboso alto se manejan conociendo el hábitat, la movilización de las especies, el tamaño de las presas, su ferocidad y velocidad, así como sus técnicas disponibles para alcanzar éxito y salir bien librados, sin heridas y sin muerte, en los objetivos de comer carne fresca.

La agricultura (terrazas y andenes en laderas) y los asentamientos arqueológicos permiten un registro tangible acerca de actividades económicas y humanas en el territorio. Ambos tipos de evidencias suponen una dicotomía que incluye muchas formas intermedias de subsistencias con sus respectivos sitios ocupacionales de tamaño diferencial, componentes de escalas sociales pequeñas, medianas y grandes, en lo que respecta a concentración demográfica a cuantificarse por sus unidades arquitectónicas componentes. Esto es real, porque los sitios varían en escala, desde el lugar donde se realiza un solo tipo de actividad hasta el asentamiento urbano complejo. También la dimensión espacial es importante en el análisis, porque es referencia de las actividades humanas: pudiéndose entonces establecer, desde una ocupación efímera o permanencia rápida, hasta siglos de duración ocupacional secuencial. Ejemplos: los cazadores móviles (permanencia rápida); lugares de descanso efímero; ocupación de larga duración (sitios con arquitectura monumental residencial, ceremonial y funeraria, plazas públicas y caminos construidos): sitios Tres Ríos, Cerro Las Cruces, Pampa Hermosa, etc. El análisis de los distintos patrones intra-sitio permite diferenciar los parámetros espacio-temporales de los indicadores interactivos demográficos y subsistenciales.

Empero, la interacción intra-sitio de mucha movilización y/o movilidad social y el patrón de interrelación inter-sitios denotan una combinación de factores medioambientales y socioculturales homogéneos, por compartir interregionalidad de recursos y cultura (clima regional, aguas, suelos, alimentos vegetales, materias primas, fauna, avifauna, organización social, sistemas económicos, sistemas de intercambio, artefactos y objetos y competencias intra-sitio e inter-sitios).

Las ciudades y pueblos Chachapoya intermedio-tardíos las encontramos relacionadas con un patrón de asentamiento territorial concentrado, distribuidos entre las cumbres de los cerros en ambas márgenes de los ríos de la región; son de próxima vecindad y se concentran en las cumbres de los cerros, los cuales han sido adecuados por medio de bancales y terrazas para cimentar las unidades constructivas. Una unidad arquitectónica está formada por una base circular de 3.00 metros promedio de altura, donde la divide una cornisa entre 0.30 á 0.40 metros de espesor promedio, y a partir de la cual se eleva la casa circular propiamente dicha con su puerta y cubierta cónica voladiza al exterior. Creemos que en la cuenca del Guabayacu hemos ubicado el desarrollo temprano de la cultura Chacha (700-800 d.C.), la cual practicaba una esfera de interrelaciones múltiples con la sierra 
interandina de ambas márgenes del río Marañón. Pero es importante señalar que los sitios iniciales alcanzaron larga duración en el tiempo, no pudiéndose cuantificar a la fecha.

Los sitios de ocupación son de patrón concentrado con unidades arquitectónicas circulares y cuadradas ornamentadas a base de motivos geométricos de cruces, roleos, rombos, zig-zag, nichos, cabezas clavas figurativas antropomorfas, zoomorfas, etc. Las edificaciones presentan dos o tres pisos de elevación superpuesta e identificamos palacios ( 2 y 3 pisos) y casas (de una sola planta). Se elevan directamente de superficies terraplenadas previamente mediante basamentos de piedras unidas con barro. En su interior, los palacios y las casas poseen pisos sólidos de lajas unidas con barro y sus muros estuvieron enlucidos en su tiempo, algunos de los cuales habrían llevado pintura parietal.

Sitios arqueológicos como Cerro Las Cruces y Cerro Central (Departamento de San Martín), y de igual manera, los de Gran Vilaya y Kuelap (Departamento de Amazonas), son residenciales, mientras que Gran Pajatén, Los Pinchudos y los Mausoleos del Guabayacu (Gran Saposoa), fueron dedicados a los rituales cultistas, las ceremonias funerarias y ritos mortuorios (Departamentos de San Martín y Amazonas).

Los Inka conquistaron la región Chachapoya hacia 1,470 d.C. con un ejército de 30,000 hombres. Construyeron el campamento militar de Pampa Hermosa, caminos empedrados y tambos (Inkapirca) para contar con apoyo logístico en alimentos, tropas de refuerzo, depósitos (comida, ropa, armas), etc. Los Chachapoya fueron impactados y conquistados por los Inka (1,470-1,535 d.C.), de manera que los materiales arqueológicos llevados por los cusqueños se convirtieron en objetos de gran prestigio para los Chacha, quienes adquieren objetos Tawantinsuyu y adicionan a sus antiguas tumbas el nuevo y prestigioso material conseguido o imitado a los cusqueños. El poder y prestigio de la cultura cusqueña fueron grandemente imitados y adoptados por los Chachapoya, quienes adicionaban a sus tumbas antiguas los nuevos y prestigiosos objetos cusqueños, considerados sagrados por los Chacha. Era, además, una práctica efectiva para incorporarse al nuevo poder impuesto por Tupa Yupanki en la región y los Inka sucesivos (Guayna Kapak, Guáskar y el emergente Atavvallpa).

De los estudios expuestos en marcha se comprende que la arqueología intermedia temprana de Markahuamachuco (Huamachuco) y Pashash (Pallasca, Ancash), dos grandes culturas interandinas de la sierra de La Libertad y Ancash, ambos de la cuenca del río Marañón, influyeron en una u otra forma para el despegue de la alta cultura compleja en el bosque nuboso alto en general (Amazonas-San Martín).

En el período intermedio-tardío Los Chacha ocuparon las cabeceras de los ríos altoandinos que discurren al monte nuboso de oeste a este, siendo las quebradas 
de esos ríos las vías naturales de acceso a las lagunas y manantes altos interandinos, así como a los productos de las tierras altas y semovientes; sus chacras para tubérculos y menestras, así como corrales para ganado, pueden ser probadas a través de acercamientos y registros por analogías etnográficas.

De los estudios realizados se propone que no es posible entender la cultura de los Chachapoya arqueológicos, si es que al mismo tiempo, no se investiga las evidencias etnográficas de la gente viviente actual del Bosque de Nubes. En los estudios etnográficos de los Jívaro en genera! se identifica actualmente a los Aguaruna, Huambisa, Nantipas, Jeberos, Achual y Shuar, distribuidos en comunidades por las márgenes del río Marañón, Chinchipe, Cenepa, Santiago, etc., hasta la Cordillera del Cóndor en la frontera con el Ecuador.

Es cierto que el avance del Tawantinsuyu al norte-nororiente encontró muy pobladas a tales comarcas. Tupa Yupanki el gran guerrero cusqueño fundó Huánucopampa (Huánuco) para avanzar a conquistar el norte-nororiente, encontrando muy poblados a los territorios entre los ríos Marañón y Huallaga.

El registro arqueológico, cruzando los datos, reconoce varios centros de poder Chacha: la cuenca del río Vilaya, la cuenca del río Utcubamba, la cuenca de los ríos Guayabamba/Guabayacu, la cuenca del río Alto Mayo, la cuenca del rio Huallaga y la cuenca del río Marañón (trayecto norte de caudal menor Pataz/Bolívar y curso nororiental de mayor caudal Cajamarca/Amazonas/San Martín/Loreto).

En tales cuencas fluviales se encuentran cantidad de sitios arqueológicos de distintas dimensiones, donde la concentración de edificaciones arquitectónicas son indicadoras de aldeas, pueblos y ciudades instaladas en las cumbres cubiertas por el monte. Es evidente que las ciudades (Kuélap, Congón, Calpunta, Vista Hermosa, Pueblo, La Pirquilla y La Mesa; Cerro Central; Cerro Las Cruces y Tres Ríos; ViraVira; Kunturmarka y Liura, etc.), jerarquizaban el poder sobre pueblos (Olán, Huamán, Monte Peruvia [Purumllaqta], Yalap, Macro, Cuémal, Tuich, Ollave, Cabildopata, Kacta, Ollape, La Jalca, Yálape, Torrepukro, Huashpa, La Joya, Pueblo Viejo, San Antonio, Los Paredones, El Turco [río Choctayacu], Monte Unión, Cedrobamba, Pampa Hermosa Alta, Lomolargo de Yonán, Patrón Samana [Chuquibamba], Cerro Chillín, etc.) y aldeas de espacios ocupados pequeños.

El análisis etno-arqueológico configura para la cultura Chachapoya, las características siguientes, respecto a los actuales habitantes nativos del nororiente:

1. Los Jívaro no tienen nombre propio, porque cada comunidad asume un nombre diferente. El término Jívaro es españolizado, quizá proviene de Xivaro y Xibaro o Xibari, indistintamente. La tradición de antigüedad de los Jívaro es legendaria en el norte-nororiente del Perú. Sus ancestros, de larga duración en el tiempo, se remontan con evidencias hasta los 3,000 años antes del 
presente; cruzando datos ancestrales encontramos que tales ancestros fueron grandes cortadores de cabezas para después reducirlas usando arena caliente y zumos vegetales del monte. Esta legendaria tradición les otorga a través de los siglos fama de feroces guerreros, constructores de una cultura compleja y poderosa nación centralizada en asentamientos jerárquicos dominantes de los principales ríos y sus valles, divididos en espacios Allauca (banda derecha) y espacios Ichoq o Ichoqan (banda izquierda) de los grandes ríos.

2. La hipótesis que planteamos, en base al cruce de datos arqueológicos y etnográficos, es que grupos Jívaro intermedio tempranos en contacto con las tierras altas hacia el oeste del bosque de nubes, recibieron influencia de las grandes culturas interandinas, como Pashash y Markaguamachuco, las que habrían sido fundamentales para los desplazamientos culturales y sociales hacia la margen derecha del Marañón, ocurriendo interrelaciones territoriales e interacciones socioculturales, que terminaron en amalgamar interpréstamos de arquitectura funeraria tipo Pashash (Pallasca) en el Complejo Gran Chivani (distrito de Uchucmarca y Chuquibamba, etc.), pasando a los complejos arquitectónicos Gran Saposoa (cuenca de los ríos Guabayacu y Guayabamba), para después corriendo los siglos, desarrollar sus propios complejos arquitectónicos urbanos, funerarios y ceremoniales, paralelos al desenvolvimiento Jívaro desplazado a las márgenes nororientales del río Marañón en su trayecto al oriente amazónico tropical bajo, donde han vivido durante el intermedio tardío y el horizonte tardío y los encontramos en la actualidad.

3. Un rápido inventario etnográfico de la cultura material de los Jívaro vivientes en nuestros días arroja el siguiente inventario:

a. Tambor de señales con cuatro agujeros en su frente; se les toca con palos labrados de tambor.

b. Flauta traversa con varios hoyuelos para digitación.

c. Tambor de dos parches laterales con su manubrio de palo y tiradores laterales.

d. Peine de numerosos palillos, sujetados por tela decorada mediante rombos horizontales unidos, como se encuentran en la arquitectura Chacha.

e. Cinta o soguilla con colgajos de maychil o madera cóncava, para sujetarse a las piernas y suenen durante la danza o movimientos rituales.

f. Agujas de madera dura o de hueso con ojal; también se hicieron puñales de estas materias, que se guardan en estuche o funda de madera. Las agujas son similares a las arqueológicas. 
g. Ollas para cocinar, de cierta similaridad a ejemplares arqueológicos.

h. Cazuelas o platos para comer.

i. Taburete para usos domésticos femeninos;

j. Taburete de pedestal cuadrado para hombres.

k. Shicras o canastas en técnica anudada o anillada, idénticas a las Shicras arqueológicas Chacha.

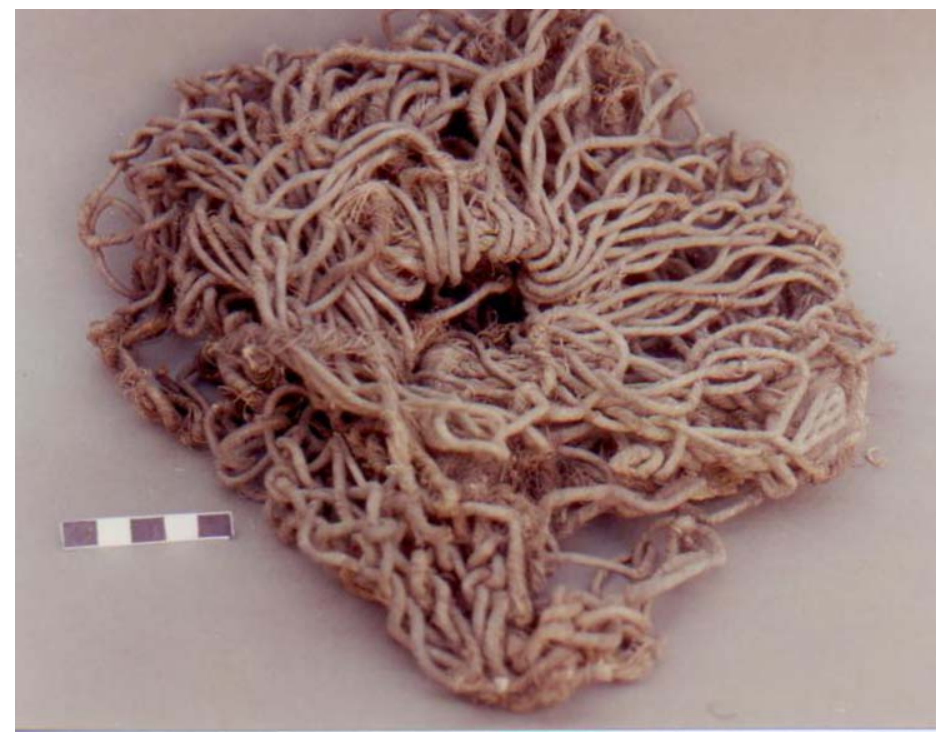

Figura .

Bolsa incompleta en fibra vegetal provedente del Mausoleo de Los Monos.

1. Huso con tortero para hilar algodón.

Los Jívaro hasta hace cincuenta años, a semejanza de los arqueológicos, vestían faldas tejidas de algodón, llevan una corona adornada con plumas de tucán en la cabeza y exhiben en el pecho cantidad de collares; hombres y mujeres se perforarían las orejas y en el agujero portan un carrizillo largo; los hombres llevaban el cabello largo o amarrado hacia atrás en una trenza, etc.; es verdad su fama de grandes guerreros, pues es práctica tradicional que armaban guerras entre las propias comunidades o se mataban por diferencias nimias. Muy buenos cazadores, pescadores y agricultores, lo cual les asegura una dieta balanceada entre proteínas e hidratos de carbono. Usaban lanzas largas de chonta decoradas con diseños geométricos como en tiempos arqueológicos, por haber sido descubiertas en el interior de tumbas Chacha durante los trabajos. 
Finalmente, es importante señalar que los Jívaro acusan mayor similaridad corporal, cultural y cultista con los Chacha, que los Chacha con los habitantes de la sierra de Cajamarca, Bolívar o Pataz.

Las ideas religiosas de los Chacha y los Jívaro etnográficos giran en torno al felino, la serpiente y el hombre/árbol, como en los tiempos arqueológicos. Las guerras Tawantinsuyu/Chacha en la región acabó y/o debilitó a los principales centros de poder Chacha, pero la gente se protegió en el monte, donde se ruralizaron y entremezclaron nuevamente con sus ancestros Jívaro. Durante la Colonia pudieron sobrevivir protegidos por el monte nuboso y en las áreas interandinas no tuvieron otra opción que aculturarse en los procesos sociales irreversibles.

\section{CRONOLOGÍA CULTURAL CHACHAPOYA}

1. Invasión Española: Gobierno Colonial.

2. El Tawantinsuyu: Atao-Wallpa, 1,532 d.C., Transición.

3. El Tawantinsuyu: Waskar, 1,527-1,533 d.C., fin Gobierno del Tawantinsuyu.

4. El Tawantinsuyu: Wayna Kayak, 1,495-1,527 d.C., Cultura Cusco expansiva.

5. El Tawantinsuyu: Tupa Yupanki, 1,470-1,495 d.C., Cultura Cusco expansiva.

6. Chachapoya Intermedio Tardío: Cuenca de los ríos Utcubamba, Gran Vilaya, Abiseo y Marañón. Construcción de la gran muralla Kuelap.

7. Chachapoya Medio: Cuenca del Río Tepna y Jelache: 900-1,000 a.C.

8. Chachapoya Temprano: Sitios y Mausoleos en la margen derecha del río Marañón y la cuenca del río Guabayacu: 500 d.C.-1,000 d.C.

9. Cueva Manachaqui VII: Intermedio Temprano: 500-700 d.C.

10. Cueva Manachaqui VI: Fase Transicional: 500-100 a.C.

11. Cueva Manachaqui V: 970-500 a.C.: Fase Formativa.

12. Cueva Manachaqui IV: Fase Suitacocha Inicial: 1,500-970 a.C.

13. Cueva Manachaqui III: Fase Lavasen, 2,170 a.C.: Precerámico Tardío.

14. Cueva Manachaqui II: 4,120 a.C.: Precerámico Temprano. Cueva Negra?

15. Cueva Manachaqui I: 8,320 a.C. Período Lítico (Cazadores y Recolectores itinerantes sierra/selva de nubes). 


\section{Bibliografía}

ANTÚNEZ DE MAYOLO, SANTIAGO.

1935 «Las minas de Tinyash (Alto Marañón)». Revista de la Esc. Nac. de Artes y Oficios, N5, Lima, pp. 345-364.

AYRES, FRED D.

1964 «The Tower and Walls of Rapayan». Peruvian Times, Vol. XXIV, Nº1253, Lima.

BONAVIA, DUCCIO.

1970 Las ruinas del Abiseo. Universidad Peruana de Ciencia y Tecnología. Lima.

BUENO MENDOZA, ALBERTO / MIGUEL CORNEJO / GENE SAVOY.

2006 «Prospecciones y excavaciones arqueológicas en la cuenca del río Guabayacu, región San Martín». En Rev. Cantuta, Nº16, Lima, pp. 57-74.

CORNEJO, MIGUEL.

1988 Investigaciones Arqueológicas en la Cuenca del Río Abiseo. Revista Yunga, N². Trujillo.

DAVIS, MORGAN.

1985 Chachapoya. The Cloud People. An Anthropological Survey (ed. mim.), Ontario.

ESPINOZA SORIANO, WALDEMAR.

1968 «Los señoríos étnicos de Chachapoya y la alianza hispano-chacha. Visitas informaciones y memoriales inéditos de 1572-1574». Revista Histórica. Tomo XXX, pp. 224-332, Lima.

FLORNOY, BERTRAND.

1956 Exploration archéologique du Alto Marañón au río Sarma. Travaux Institut Francais d'Etudes Andines. Vol. V, Lima-París.

1957 «Monuments de la Región de Tantamayo». Journal de la Societé des Americanistés, Tomo XLVI, Nouvelle serie. París.

KAUFFMAN DOIG, FEDERICO.

1986a «Sarcófagos preincas en los Andes Amazónicos Peruanos». Revista Kuntur.

Perú en la Cultura 1, pp. 4-9. 
KAUFFMAN DOIG, FEDERICO Y OTROS.

1990 Andes Amazónicos: sitios intervenidos por la Expedición Antisuyo/86. En Revista. Arqueológicas, $\mathrm{N}^{\circ} 20$, Lima.

KAUFFMAN DOIG, FEDERICO Y GIANCARLO LIGABUE.

2003 Los Chachapoya(s). Moradores Ancestrales de los Andes Amazónicos Peruanos. Universidad Alas Peruanas, Lima, 485 pp.

MUSCUTT KEITH.

1998 Warriors of the clouds. A lost civilization in the upper amazon of Perú. University of New México Press, Albuquerque.

REICHLEN, HENRY ET POULET REICHLEN.

1951 «Recherches archéologiques dans les Andes du haut Utcamba». Journal de la Societé des Americanistés, Tomo XXXIX, pp. 219-46, París.

ROJAS PONCE, PEDRO.

1968 «The ruins of Pajatén». Archaeology, Vol. 20, N¹, Brattleboro.

SAVOY, GENE.

1965-1968 A series of ever 20 popular art articles and press releases on his explorations published in the Peruvian Times. Vols. XXV, N¹294, to XXVIII, N¹435, Lima.

1969 Antisuyo: The Search for the Last Cities of the Amazon. Simón and Schuster, New York.

1971 Antisuyo: The Search for the Last Cities of the Amazon. Simón and Schuster, New York. (Segunda Edición).

VEGA OCAMPO, ABEL.

1977 «El Complejo Arqueológico de Uchucmarca y el Conjunto de Pirka Pirka». En Revista Universitaria, año XIX, N³0, Trujillo.

VREELAND, JAMES Y FEDERICO KAUFFMAN DOIG.

1989 «Una tela monumental del área del Pajatén» (Abiseo). Revista del Museo Nacional, Lima.

ZEVALLOS QUIÑÓNEZ, JORGE.

1982 «Onomástica prehispánica de Chachapoya». En: Revista Investigación Arqueológica, $\mathrm{N}^{\circ} 4$, Trujillo, pp.4-18. 